\title{
Impacts of wood extraction on soil: assessing rutting and soil compaction caused by skidding and forwarding by means of traditional and innovative methods
}

\author{
Elena Marra ${ }^{1}$ (1) Andrea Laschi ${ }^{2}$ (1) Fabio Fabiano $^{1} \cdot$ Cristiano Foderi $^{1} \cdot$ Francesco Neri $^{1} \cdot$ Giovanni Mastrolonardo $^{1}$. \\ Tomas Nordfjell ${ }^{3} \cdot$ Enrico Marchi $^{1}$
}

Received: 20 January 2021 / Revised: 15 September 2021 / Accepted: 23 September 2021 / Published online: 17 November 2021

(C) The Author(s) 2021

\begin{abstract}
Intensive forestry operations may cause soil compaction, plastic soil disturbances and rutting, which are responsible for undesirable effects on soils, vegetation and water bodies. Despite the numerous studies aimed to identify the main factors affecting soil damages, it still remains unclear whether wood extraction methods and driving direction (uphill or downhill) may affect the impacts of forest machines. This research analyses soil compaction and soil penetration resistance as well as rutting from forwarding and skidding using the same farm tractor in up- and downhill wood extraction. Rutting was estimated by 3D soil reconstruction derived by portable laser scanning (PLS) and close-range photogrammetry using structure for motion (SfM). Our findings showed that the direction of extraction did not affect soil damage severity during forwarding on a $25 \%$ slope. On the contrary, in order to reduce soil compaction, downhill skidding is preferable to uphill skidding. The results showed that the pressure on the ground caused by vehicles can be distributed horizontally, thus affecting also the soil between the wheel tracks. The soil bulk density inside the tracks after 10 forwarding passes increased by $40 \%$ and with $23 \%$ between the wheel tracks. The soil displacement in skidding trails $\left(7.36 \mathrm{~m}^{3}\right.$ per $100 \mathrm{~m}$ of trail $)$ was significantly higher than in forwarding $\left(1.68 \mathrm{~m}^{3}\right.$ per $100 \mathrm{~m}$ of trail). The rutting estimation showed no significant difference between the PLS and SfM methods, even comparing the two digital surface models (DSMs) obtained, even if photogrammetry was preferred for technical and practical reasons.
\end{abstract}

Keywords Portable laser scanner $\cdot$ Digital elevation model $\cdot$ Soil disturbance

Communicated by Eric R. Labelle.

Andrea Laschi
andrea.laschi@unipa.it
Elena Marra
elena.marra@unifi.it
Fabio Fabiano
fabio.fabiano@unifi.it
Cristiano Foderi
cristiano.foderi@unifi.it
Francesco Neri
francesco.neri@unifi.it
Giovanni Mastrolonardo
giovanni.mastrolonardo@unifi.it
Tomas Nordfjell
tomas.nordfjell@slu.se

Enrico Marchi

enrico.marchi@unifi.it

1 Dipartimento di Scienze e Tecnologie Agrarie, Alimentari, Ambientali e Forestali (DAGRI), University of Florence, Via San Bonaventura 13, 50145 Florence, Italy

2 Dipartimento di Scienze Agrarie, Alimentari e Forestali (SAAF), Università degli Studi di Palermo, Viale delle Scienze ed. 4, 90128 Palermo, Italy

3 Department of Forest Biomaterials and Technology (SLU), Swedish University of Agricultural Sciences, Skogsmarksgränd, Umeå, Sweden 


\section{Introduction}

Soil disturbance is an unavoidable consequence of timber logging, but the severity of its impact is variable and can be managed through good planning and practices (Ares et al. 2005). According to the SFO (sustainable forest operation) concept, the minimization of soil impacts is a key task to improve the environmental efficiency of timber logging (Marchi et al. 2018). Intensive forestry operations may cause soil compaction, plastic soil disturbances and rutting, which are responsible for undesirable effects on soils, vegetation and water bodies (Cambi et al. 2015). Ground-based logging operations can negatively affect soil physical characteristics, reducing porosity while also increasing bulk density and resistance to mechanical penetration (Siegel-Issem et al. 2005; D'Acqui et al. 2020; Lee et al. 2020). Moreover, soil compaction indirectly influences tree growth and regeneration due to both physical root damage and reduced soil permeability (Cambi et al. 2018a, 2018b; Jansson and Wasterlund 1999; Mariotti et al. 2020; Sirén et al. 2013; Solgi et al. 2019; Sugai et al. 2020), which may lead to deficiencies of oxygen, water and/or nutrients (Batey 2009; Lee et al. 2020) with recovery processes that may take several decades (Bottinelli et al. 2014; Jourgholami et al. 2020). Rutting and other soil disturbances can also disperse pathogenic fungi, alter microbiological processes (Frey et al. 2009; De Wit et al. 2014; Cambi et al. 2017) and mobilize heavy metals due to the increase in surface water flow (Frey et al. 2009; De Wit et al. 2014; Eklöf et al. 2014). Depending on logging conditions (e.g. soil condition and type, wood extraction method, machine characteristics and operator skills), the surface affected by disturbance within the logging area may range widely from 10 to $87 \%$ (Spinelli et al. 2010; Marchi et al. 2014; Naghdi et al. 2015).

Several studies were published on the impact of logging on soil in recent years; in this field, the most important factors affecting compaction and rutting on forest soils and their relationships and interactions, such as slope gradient, driving direction (uphill vs. downhill), extraction method (skidding vs. forwarding), still need to be examined in depth. This is fundamental to be able to plan effective mitigation strategies. Some studies highlighted the effect of slope on soil compaction, finding that the higher the terrain slope, the higher the impact on soil (Jamshidi et al. 2008; Jourgholami et al. 2014; Naghdi et al. 2020). Previous studies have also investigated the impact caused by skidding and forwarding, highlighting that the extent of surface disturbance was higher after skidding, whereas compaction showed contrasting results between the two systems (Lanford and Stokes 1995; Deconchat 2001; Gondard et al. 2003; Cambi et al. 2018a). Compared to forwarders, skidders are driven in a denser extraction trail network (Han et al. 2009) with lower loads, thus explaining the greater extent of surface damages. In forwarding, the impacts on soil are related only to the contact of tyres on the ground (rut formation), whereas in skidding, the semi-dragged logs also contribute to soil impact (soil displacement). In general, impacts on soil due to skidding have been more closely studied than forwarding. In addition, neither data nor studies have been found that compare the effects on soil caused by skidding and forwarding considering a similar operational context, which highlights a gap in the literature.

In recent years, innovative tools that are useful in assessing soil surface disturbances have become available. For the measurement of rutting which relied on classical manual measurements (Jester and Klik 2005) are now available some innovative techniques such as three-dimensional ground reconstruction derived by photogrammetry (Pierzchała et al. 2014, 2016; Haas et al. 2016; Marra et al. 2018; Talbot et al. 2018) or laser scanning (Koreň et al. 2015). In particular, portable laser scanners (PLS) have started to be used in forestry for rutting estimation (Giannetti et al. 2017). However, sizeable knowledge gaps are evident concerning the efficacy of these newer methods (i.e. PLS and close-range photogrammetry) in the impact assessment of forest operations.

The objective of this research was to study the effects of timber extraction on steep terrain by measuring bulk density (BD), penetration resistance (PR) and surface disturbances such as rutting, considering both the extraction method (skidding and forwarding) and driving direction (uphill and downhill). Also, the application of two new methods such as $3 \mathrm{D}$ soil reconstructions derived by both portable laser scanner and close-range photogrammetry using Structure for Motion (SfM) were tested for measuring rutting and to identify the most suitable for applications in a forest context.

\section{Materials and methods}

\section{Site description and experimental design}

The fieldworks for this study were carried out from June 15 to July 5, 2018, in the Rincine forest, a public forest property located in the north-east part of Florence province, $40 \mathrm{~km}$ outside the Florence town (central Italy, N 4352'; E 11 $34^{\prime}$; $400 \mathrm{~m}$ above sea level). Considering climate data from the last 30 years, the climate of the study site has been classified as Mediterranean (Köppen-Geiger classification), characterized by a hot, dry summer (with January as the coldest month and August the hottest). In the period 2017-2018, the local mean annual temperature was $9.2{ }^{\circ} \mathrm{C}\left(1.5^{\circ} \mathrm{C}\right.$ in the coldest months and $17.8{ }^{\circ} \mathrm{C}$ in the warmest), and the mean annual precipitation was $924 \mathrm{~mm}$, with the maximum 
in November and the minimum in July. The soil of the study site developed on Lower Miocene-Oligocene sandstone and was classified as Dystric Cambisol based on the World Reference Base for Soil Resources (IUSS Working Group 2014). The study site was identified within a 50-year-old high stand of Douglas Fir, located $900 \mathrm{~m}$ above sea level, characterised by a density of $800 \mathrm{stems} \cdot \mathrm{ha}^{-1}$ and trees with $40 \mathrm{~cm}$ of average diameter and $25 \mathrm{~m}$ of average height. At the time of the study, no logging activities had been conducted within the study area in the last 40 years, thereby avoiding any influence of previous logging operations. Moreover, no silvicultural treatments were made during the study to avoid additional and unpredictable variables, focusing only on the extraction operations. These were made using a set of Douglas Fir logs extracted in a similar parcel next to the study area. Four trails were designed on the ground in the direction of the slope. Two trails were used for forwarding and two for skidding; in both extraction methods, one trail was used uphill and the other downhill (Fig. 1). All trails had the same slope (25\%). On these trails, wood extraction cycles were simulated using a four-wheel driven agricultural tractor adapted to work in forestry for skidding (equipped with a winch) or forwarding (equipped with forest trailer) Douglas Fir logs. These machines are very common in forest operations in Italy, especially in peninsular forests, and more generally throughout the Mediterranean area. The tractor was a New Holland T6050 (power $93 \mathrm{~kW}$ ), the winch a Farmi JL61 and the trailer a Zaccaria ZAM 140 Forestal TC
Super. The trailer had two axles with two wheels each; the front axle was powered by the mechanical transmission from the power take off (PTO) from the tractor, while the rear one was a not powered self-steering axle. Technical characteristics of the machines are summarized in Table 1 . The contact areas shown in the table were measured by means of a rope pulled tightly around the portion of the tyre on the ground and assuming a circular contact patch (Cambi et al. 2016). Ground contact pressure was calculated as a ratio between the machine mass and the contact area (Table 1).

The tractor (in both configurations, with trailer or winch) moved on the four new trails designed within the stand to monitor physical parameters and rutting before and after machine traffic. The tractor operator was an experienced forest worker who drove as in a standard operation along the trail. Three rectangular plots (length $3 \mathrm{~m}$, width $6 \mathrm{~m}$ ) were selected and marked on the ground along each straight trail section (Fig. 1).

Volume and number of logs loaded in skidding and forwarding are reported in Table 2. The volume of each log was calculated applying Cavalieri's formula:

$V_{l}=\frac{S_{t}+S_{b}+4 S_{0.5}}{6} \cdot h$

where: $V_{l}=$ volume of the $\log ; S_{t}=$ section at top-end; $S_{b}=$ section at bottom-end; $S_{0.5}=$ section at half length; $h=$ length. Regarding the weight of $\operatorname{logs}$, it has been

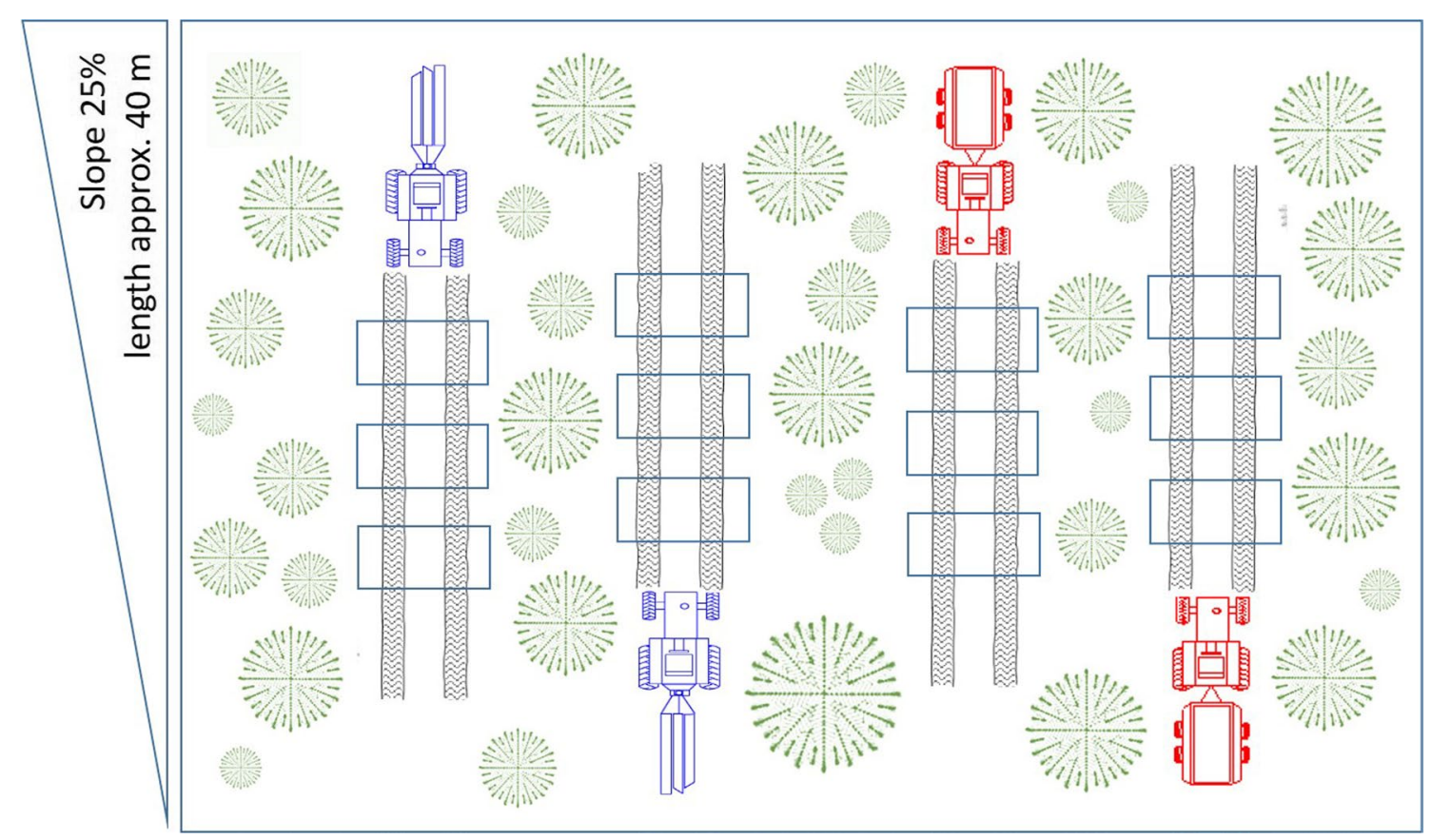

Fig. 1 A representation of the plots included in the 4 trails. Two directions of extraction—uphill and downhill—were examined for both skidding and forwarding. In blue, tractor with winch is represented, while tractor and trailer is in red 
Table 1 Main characteristics of the machines used

\begin{tabular}{|c|c|c|c|c|c|}
\hline \multirow{4}{*}{$\begin{array}{l}\text { Model } \\
\text { Tyre model }\end{array}$} & \multicolumn{2}{|l|}{ Tractor } & \multicolumn{2}{|l|}{ Trailer } & \multirow{4}{*}{$\begin{array}{l}\text { Winch } \\
\text { Farmi JL61 } \\
- \\
-\end{array}$} \\
\hline & \multicolumn{2}{|c|}{ New Holland T6050 } & \multicolumn{2}{|c|}{ Zaccaria ZAM 140 Forestal TC } & \\
\hline & \multicolumn{2}{|c|}{ Michelin TD MULTIBIB } & \multicolumn{2}{|c|}{ BKT FLOTATION 648} & \\
\hline & Front axle & Rear axle & Driven front axle & $\begin{array}{l}\text { Self-steering } \\
\text { non driven rear } \\
\text { axle }\end{array}$ & \\
\hline Weight without load (kg) & 2962 & 3228 & 4750 & & 555 \\
\hline Tyre size* & $480 / 65$ R28 & $600 / 65$ R38 & $385 / 65-22.5$ & $385 / 65-22.5$ & - \\
\hline Tyre inflation pressure $(\mathrm{kPa})$ & 100 & 100 & 375 & 380 & - \\
\hline Tyre contact area $\left(\mathrm{cm}^{2}\right)$ & 2710 & 5018 & $1473^{* *}$ & $1516^{* *}$ & - \\
\hline Tyre contact pressure $(\mathrm{kPa})$ & 54 & 32 & $196^{*}$ & $155^{*}$ & \\
\hline Wheels (n) & 2 & 2 & 2 & 2 & - \\
\hline
\end{tabular}

*Width (mm)/height (\%) wheel rim diameter (inches). **Trailer loaded with $7022 \mathrm{~kg}$ of logs

\begin{tabular}{llllllc}
\hline & $\begin{array}{l}\text { N. logs } \\
\text { extracted per } \\
\text { passage }\end{array}$ & $\begin{array}{l}\text { Average log } \\
\text { diameter }(\mathrm{m})\end{array}$ & $\begin{array}{l}\text { Average log } \\
\text { length }(\mathrm{m})\end{array}$ & $\begin{array}{l}\text { Load } \\
\text { volume } \\
\left(\mathrm{m}^{3}\right)\end{array}$ & $\begin{array}{l}\text { Load volume } \\
\text { after 10 passes } \\
\left(\mathrm{m}^{3}\right)\end{array}$ & $\begin{array}{l}\text { Load volume } \\
\text { after 45 passes } \\
\left(\mathrm{m}^{3}\right)\end{array}$ \\
\hline Forwarding & 38 & 0.29 & 5.09 & 12.77 & 127.68 & - \\
Skidding & 9 & 0.27 & 5.30 & 2.82 & 28.17 & 126.77 \\
\hline
\end{tabular}

To simulate the extraction of the same volume of logs, 45 skidding and 10 forwarding passes were made
Table 2 Characteristics of $\log$ used for loading the winch in skidding and the trailer in forwarding
Before machine traffic, three soil samples were collected approximately one meter from each identified trail, on both the left and right sides, for a total of six samples per plot. After the machine passes (10 forwarding passes and 10 and 45 for skidding), three soil samples were collected inside both left and right wheel tracks (InR) and three samples were collected between the tracks (BtwR), for a total of nine samples per plot (Fig. 2). All soil samples were collected from the top $10 \mathrm{~cm}$ of mineral soil layer, using a metal cylinder $(7.5 \mathrm{~cm}$ inner diameter and $10 \mathrm{~cm}$ height). BD was calculated as the dry-weight (after a treatment at $105^{\circ} \mathrm{C}$ per $48 \mathrm{~h}$ ) of the soil sample divided by the volume of the sampler (Picchio et al. 2009). In addition, six soil samples were collected daily from the trails (outside the plots) in order to monitor the soil moisture over time (soil moisture content on a dry-weight basis).

The PR was measured by a hand cone penetrometer (Field Scout SC 900). A cone with a diameter of $12.7 \mathrm{~mm}$ and cone angle of $30^{\circ}$ was used to register the average penetration resistance in the first $10 \mathrm{~cm}$ of the soil (at each $2.5 \mathrm{~cm}$ of soil depth). In each plot, PR was measured following the same protocol as BD (3 samples each in InR and 3 in BtwR) as an average of three values collected in each sample point.

\section{Rut measurements}

Two methods to implement a 3D soil reconstruction, derived by both portable laser scanner (hereafter PLS) and 


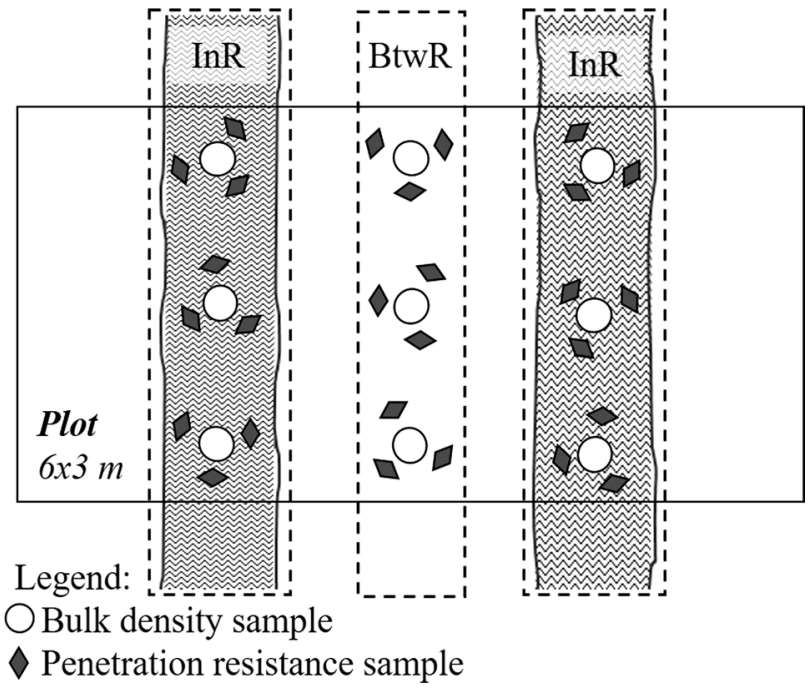

Fig. 2 Scheme of soil sample and data collection on the trails for physical soil characteristics after machine passes. On each trail, the data were collected within the track (InR) and between the tracks (BtwR). The circles indicate soil samples collected for bulk density; the diamonds indicate penetration resistance measurements

close-range photogrammetry using structure for motion (hereafter SfM), were applied to measure rutting caused by machine traffic on forest soil. Measurements and data acquisition took place in the same plots used for collecting the other soil physical parameter data. Each method may provide accurate information about changes to the ground surface caused by the passage of forest machines by generating 3D representations of the trail section before and after the machine passes. The 3D soil reconstructions derived by both PLS and SfM were used for determining the volume of ruts caused by machine wheels and/or by dragged logs after skidding and forwarding, thereby allowing for the calculation of differences between digging and carryover soil volume.

\section{SfM data collection and pre-elaboration}

\section{Data collection}

The application of SfM is based on a series of images collected in the field. In our study, these images were collected using an RGB reflex camera: a Canon EOS 1300D model with $18 \mathrm{MP}$ of image resolution and $5184 \times 3456$ pixels. The camera, which has a focal length of $18 \mathrm{~mm}$, was mounted on a tripod $3 \mathrm{~m}$ in height with an angle of $45^{\circ}$. Image acquisition followed a specific scheme, previously described in Marra et al. (2018), designed to collect several images every half meter in different directions. All the images collected were checked directly in the field, immediately after collection, by visual interpretation to detect eventual problems

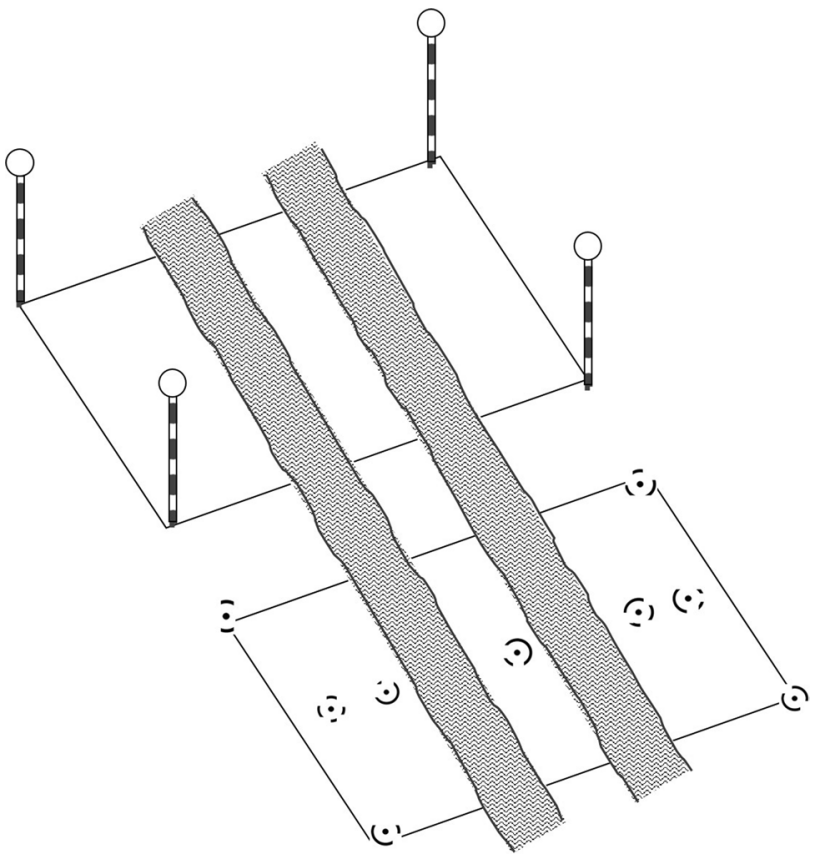

Fig. 3 Position of the Ground Control Points during laser scanning (above) and close-range photogrammetry (below) data collection

related to light, saturation and blurriness, recollecting lowquality. Before the acquisition of the images, nine ground control points (GCPs) were positioned on each plot for image geolocation (Fig. 3). GCPs were composed of Schneider's coded target (Schneider 1991), an automatically recognizable feature generated with Agisoft Photoscan ${ }^{\circledR}$ software (Agisoft 2016). In detail, each GCP was a $144 \mathrm{~cm}^{2}$ square aluminium plate with a specific printed image. The image was characterized by a central dot (radius of $15 \mathrm{~mm}$ ) surrounded by a code band (12-bit pattern) with bit positions at equally spaced angular intervals (black or white). A local system of coordinates was created and the $\mathrm{X}, \mathrm{Y}$, and Z coordinates of each GCP were measured and used to align the models acquired at different phases.

\section{Pre-elaboration}

The SfM technique was applied to photo analyses to obtain 3D georeferenced point clouds. The analysis has been implemented in several steps using the Agisoft Photoscan ${ }^{\circledR}$ photogrammetric software package: (i) image import, (ii) image alignment, (iii) georeferencing, (iv) optimization of image alignment and (v) creation of the point and dense clouds.

After a rough alignment of loaded photos, the camera positions were optimised through the automatic detection and matching of GCPs using a specific functionality of Agisoft Photoscan ${ }^{\circledR}$. This guaranteed sub-pixel accuracy without the need for human interventions. Thanks to camera optimisation and GCP detection, the single dense point 
cloud was produced to determine the 3D soil reconstruction of each plot point at each collection time. All workflow was elaborated using Python 3.5 (Van Rossum and Drake 2020) as a scripting engine and supported by Agisoft Photoscan ${ }^{\circledR}$.

\section{PLS data collection and pre-elaboration}

\section{Data collection}

A lightweight, portable ZEB1 HMLS consisting of a 2D laser scanner (Geoslam: Ruddington, Nottinghamshire 2016), combined with an inertial measurement unit (IMU), was used to scan the plots within the study area collecting spatial data (acquisition speed 43,200 points/sec). The reported outdoor operative laser range is $15-20 \mathrm{~m}$ around the instrument (Bosse et al. 2012; Giannetti et al. 2017) with a scan ranging noise of $\pm 30 \mathrm{~mm}$. In each plot, four GCPs were mounted as spherical targets (diameter $=0.14 \mathrm{~m}$ ) at the top of $1.5 \mathrm{~m}$ poles (Fig. 3) fixed in the ground at the corners of the plot. The X, Y and Z coordinates of each GCP were measured in the same systems of coordinates implemented for SfM, thereby guaranteeing the correct overlapping of results for comparison. To collect data in the plots (Fig. 4), the operator walked slowly (approximately $30 \mathrm{~cm} \mathrm{~s}^{-1}$ ) holding and oscillating the instrument at breast height $(1.40 \mathrm{~m}$ above ground). The route inside the plot area was covered by walking the entire plot surface back and forth along straight lines (spaced $0.5 \mathrm{~m}$ apart), beginning and ending the survey at the same point (Ryding et al. 2015). In order to avoid shadow zones and to obtain the highest scan density of GCPs, special care was taken to fully scan the spherical targets.

\section{Pre-elaboration}

The 3D georeferenced point cloud was calculated from raw data by an online service (Geoslam: Ruddington,

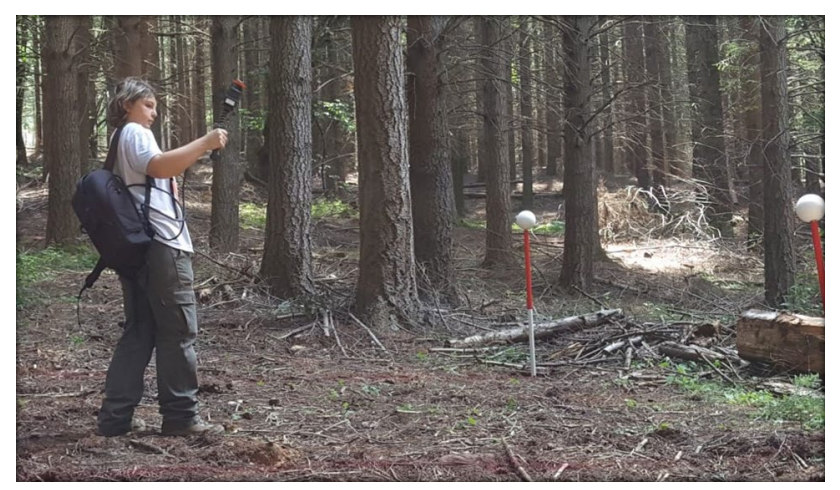

Fig. 4 Operator during laser scanner survey, holding and oscillating the instrument at breast height $(1.30 \mathrm{~m}$ above ground $)$ while walking
Nottinghamshire 2016) provided by the producer of the ZEB1 laser scanner. This procedure uses a novel 3D simultaneous localization and mapping algorithm (SLAM) to combine the 2D laser scan data with the IMU data to generate accurate 3D point clouds (Bauwens et al. 2016). The resulting point clouds were loaded in CloudCompare (CloudCompare Version 2.112020 ) in.las file format and then 'cleaned' to detect the plot and remove non-soil objects, such as stumps and trees. This process included the following steps: (i) identifying the plot in the point cloud by visual interpretation of GCPs, (ii) manually tracking and segmenting the plot, and (iii) georeferenced processing of each GCP.

\section{Quantification of rutting}

\section{Co-registration of point clouds}

The point clouds for both methods used were elaborated by CloudCompare software to obtain the digital surface models (DSM) before and after forest machines passes in all plots. First, the soil surface conditions before (i.e. reference cloud) and after (i.e. compared clouds) machine traffic were coregistered in CloudCompare using the GCPs and analysed using the 'point pair-based alignment tool'. A fast control was conducted to assess the reliability of the automatic cloud's overlap. In addition, minimum errors in positioning were eliminated through a calibration of the coordinate system considering the root-mean-square error (approximately $4 \mathrm{~cm}$ ) for vertical and horizontal displacement. Finally, the point clouds were rasterized considering the average $\mathrm{Z}$ coordinate to create high-resolution (pixel $=1 \mathrm{~cm}$ ) DSMs for each plot.

\section{Rut measurement estimations}

The differences between the DSMs before and after machine traffic were implemented in CloudCompare in order to determine the volumes of ruts (volume reduction $=\mathrm{VR}$ ) and bulges (volume increased $=\mathrm{VI}$ ) caused by machine wheels or dragged logs. In addition, all the DSMs derived by SfM and PLS had the same resolution $(601 \times 301$ pixels $)$ to compare accuracy, pixel by pixel, with the R-cran raster packages (Hijmans et al. 2020).

\section{Physical parameters and rutting: analysis of data}

Statistical analyses were performed using R software ( $R$ Development Core Team 2020). After checking for normality (Pearson chi-square test) and homogeneity of variance (Bartlett test), multi-way ANOVA was applied to the BD in order to test the soil compaction effects by machine type, impacted zone (InR or BtwR), driving direction (uphill or downhill), number of passes and total volume moved. A post 
hoc LSD test (least significant difference test) was applied to rank the results between dependent significant variables. Statistical differences in soil moisture at the time of each field day were tested by means of a t test. The Kruskal-Wallis nonparametric multiple-comparison test (Dunn's test) was used to PR data because data distribution was not normal and variances were not homogeneous. Regarding the analysis on rutting, to verify the accuracy of DSMs obtained with SfM and PLS, regression analyses and the root-mean-square error (RMSE) were performed. Finally, the soil volume changes (VI and VR) were compared by applying a oneway ANOVA in order to understand the effects of the wood extraction methods and to compare the volume estimation with SfM and PLS.

\section{Results}

\section{Physical soil parameters}

In the study site, the average soil moisture was $18 \%$ throughout the entire study period. BD and PR were significantly affected by machine passes. During forwarding, a larger load than skidding was transported in each pass. However, a higher number of skidding passes was required to extract the same wood volume than in forwarding (10 passes in forwarding and 45 in skidding, to obtain $127 \mathrm{~m}^{3}$ wood volume moved). In detail, the weight of the vehicles and their loads for each pass was 17,962 kg in total for forwarding (7022 kg of load) and $8294 \mathrm{~kg}$ for skidding (1549 kg of load). The total weight transported on the ground of the study site after the woods extraction, was higher for skidding $(373,246 \mathrm{~kg})$ than for forwarding $(179,624 \mathrm{~kg})$ on the study site.

\section{Bulk density—BD}

The BD measured within the plots (both InR and BtwR) was significantly higher than in the undisturbed soil before the trials (Table 3).
Comparison of $\mathrm{BD}$ considering the same number of passes in skidding and forwarding After 10 passes, in both skidding $\left(28 \mathrm{~m}^{3}\right.$ of wood volume transported on the trails) and forwarding (127 $\mathrm{m}^{3}$ of wood volume transported), a significant increase of the BD values was found (Table 3). BD was not affected by the driving direction; however, it was significantly affected by the logging method applied and the impacted zone (InR or BtwR). In general, skidding showed significantly lower values of BD in InR than forwarding, while similar BD values were recorded in BtwR. Finally, when forwarding moving both uphill and downhill, the increase in BD InR (40\% higher than control on average; range $25 \%-52 \%$ ) was significantly higher than the increase in BD BtwR (23\% higher than control on average). After skidding operations, an average increase of $30 \%$ (range $17 \%-40 \%$ ) was recorded in both BD InR and BtwR.

Comparison of BD considering the same wood volume moved by both skidding and forwarding Increasing the number of skidding passes to simulate extraction of the same wood volume by forwarding $\left(127 \mathrm{~m}^{3}\right)$ affected the measured values of BD. Comparing the effects of the two extraction methods, the results showed similar BD values when operating uphill, while when working downhill, skidding showed significantly lower values of $\mathrm{BD}$ in $\mathrm{InR}$ - and significantly higher values of $\mathrm{BD}$ in BtwR - than forwarding (Fig. 5). Thus, the highest average values of $\mathrm{BD}$ were obtained in InR, in both uphill and downhill directions for forwarding, but only in uphill for skidding (approximately $40 \%$ higher than undisturbed soil). On the other hand, the effects on soil in BtwR were lower than in InR, except when using the tractor with winch downhill, in which case the dragged logs caused a greater increase of BD in BtwR than the tyres in InR.

As reported in Table 4, the analysis of variance showed a strong influence of both the wood extraction methods and the impacted zone (InR/BtwR) on soil compaction after machine traffic, in terms of BD. Moreover, a significant effect of driving direction (uphill vs. downhill) was recorded only after 45 passes. The statistical difference between InR and BtwR was strongly significant both
Table 3 Mean values of bulk density BD $( \pm \mathrm{SD})$ after 10 passes by skidding and forwarding in different driving directions (uphill or downhill) measured both inside (InR) and between (BtwR) the tracks

\begin{tabular}{|c|c|c|c|c|}
\hline Bulk density-BD $\left(\mathrm{g} / \mathrm{cm}^{3}\right)$ & \multicolumn{2}{|c|}{$\begin{array}{l}\text { Extraction method; } \\
\text { No. passes: } \\
\text { wood volume transported }\end{array}$} & $\begin{array}{l}\text { Skidding; } \\
10 \text { passes; } \\
28 \mathrm{~m}^{3}\end{array}$ & $\begin{array}{l}\text { Forwarding; } \\
10 \text { passes; } \\
127 \mathrm{~m}^{3}\end{array}$ \\
\hline Before machine traffic & & & $0.86(0.07)^{\mathrm{a}}$ & \\
\hline After 10 passes & Uphill & $\begin{array}{l}\text { InR } \\
\text { BtwR }\end{array}$ & $\begin{array}{l}1.08(0.07)^{\mathrm{cd}} \\
1.05(0.06)^{\mathrm{bcd}}\end{array}$ & $\begin{array}{l}1.17(0.06)^{\mathrm{e}} \\
1.03(0.05)^{\mathrm{bc}}\end{array}$ \\
\hline After 10 passes & Downhill & $\begin{array}{l}\text { InR } \\
\text { BtwR }\end{array}$ & $\begin{array}{l}1.09(0.09)^{\mathrm{d}} \\
1.06(0.07)^{\mathrm{bcd}}\end{array}$ & $\begin{array}{l}1.18(0.07)^{\mathrm{e}} \\
1.02(0.03)^{\mathrm{b}}\end{array}$ \\
\hline
\end{tabular}

Superscript letters show statistically significant differences $(p$-value $<0.05)$ 


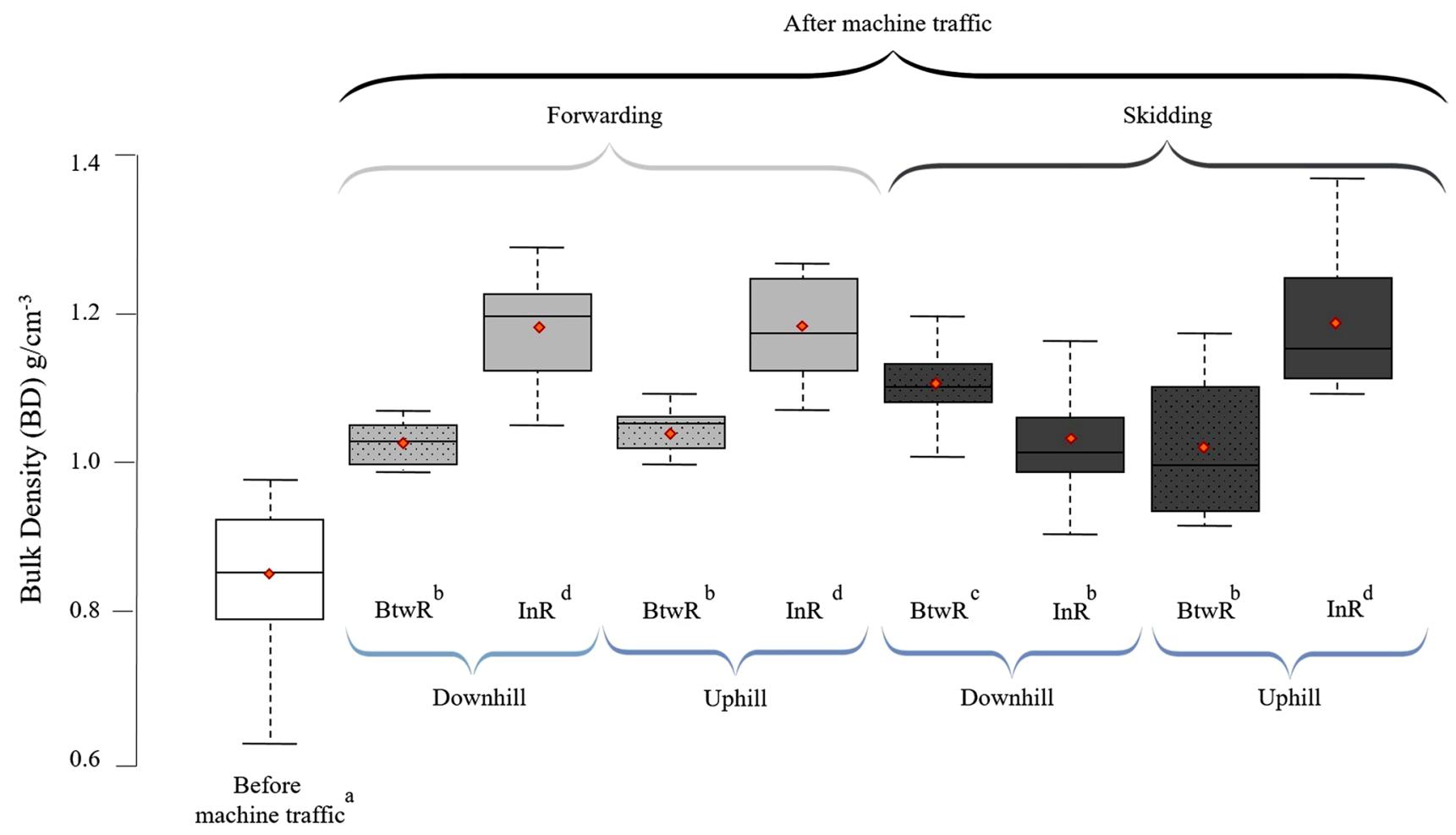

Fig. 5 Average values of bulk density (red diamonds) after 127 $\mathrm{m}^{3}$ of wood passed on the trails (including median and spreading range) by 10 and 45 passes for skidding and forwarding, respec-

pling zone (inside tracks-InR - and between tracks-BtwR) are included. Superscript letters show statistically significant differences $(p$-value $<0.05)$ tively. Data about driving direction (uphill or downhill) and sam-

Table 4 Analysis of variance ( $p$-values) of the effects of wood extraction method (skidding and forwarding), driving direction (uphill and downhill), impacted zone (inside the ruts $=\mathrm{InR}$ or between the ruts $=$ BtwR) and the interactions on bulk density (BD) after 10 passes and after $127 \mathrm{~m}^{3}$ of wood volume moved

\begin{tabular}{lll}
\hline Source of variance & \multicolumn{2}{l}{$p$-values } \\
\cline { 2 - 3 } & Bulk density & \\
\cline { 2 - 3 } & After 10 passes & $\begin{array}{l}\text { After } 127 \mathrm{~m}^{3} \text { of } \\
\text { wood volume } \\
\text { moved }\end{array}$ \\
\hline Wood extraction methods & & $*$ \\
Driving directions & $* *$ & $*$ \\
InR vs. BtwR & - & $* * *$ \\
Wood extraction method $\times$ Driving directions & $* * *$ & $*$ \\
Wood extraction method $\times$ InR vs. BtwR & - & $* *$ \\
Driving directions $\times$ InR vs. BtwR & $* * *$ & $* * *$ \\
Wood extraction methods $\times$ Driving directions $\times$ InR or & - & $* * *$ \\
BtwR & - & \\
\hline
\end{tabular}

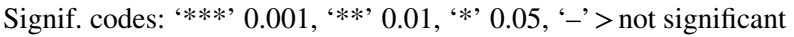

after 10 passes and $127 \mathrm{~m}^{3}$ moved. Analysing multiple interactions for $\mathrm{BD}$, significant ones were found for wood extraction method and driving direction and between driving direction and impacted zone only when considering the same wood volume moved, while those interactions were not-significant when considering the same number of passes. The interaction between wood extraction method and impacted zone (BtwR vs. InR) was stronger when considering the same number of passes than the same volume moved. Finally, the interaction among wood extraction method, driving direction and impacted zone was strongly significant when considering the same wood volume moved. 


\section{Penetration resistance-PR}

\section{Comparison of PR considering the same number of passes} in skidding and forwarding After 10 passes of tractor with trailer (i.e. $127 \mathrm{~m}^{3}$ moved), only the values of PR recorded within the tracks (InR) were significantly higher than the control (untrafficked) (Table 5). The PR values between the tracks (BtwR) did not change significantly. When considering the forwarding direction, significant differences were found between InR and BtwR when the tractor with trailer was driven uphill. Any statistical difference was recorded in skidding after 10 passes (i.e. $28 \mathrm{~m}^{3}$ moved) for both driving direction and within (InR) or between tracks (BtwR). The comparison of skidding and forwarding did not show any significant difference, neither for driving direction nor InR/ BtwR. The highest value of PR was recorded in forwarding uphill InR. This value was significantly higher than that recorded in skidding downhill InR and BtwR.

Comparison of PR considering the same wood volume moved by both skidding and forwarding Further increments in PR (both InR and BtwR) were recorded in skidding trails after 45 passes (i.e. $127 \mathrm{~m}^{3}$ - the same wood volume moved by forwarding). Increasing the number of passes, PR did not show any significant differences among skidding treatments (Fig. 6). Comparing skidding and forwardingand considering the same wood volume moved-the results highlighted that the lower PR values were recorded in for-
Table 5 Mean penetration resistance PR $( \pm$ SD) after 10 passes by skidding and forwarding in different driving directions (uphill or downhill) measured both inside (InR) and between (BtwR) the tracks

\begin{tabular}{|c|c|c|c|c|}
\hline Penetration resistance- $-\mathrm{PR}(\mathrm{kPa})$ & \multicolumn{2}{|c|}{$\begin{array}{l}\text { Extraction method } \\
\text { No. passes; } \\
\text { wood volume moved }\end{array}$} & $\begin{array}{l}\text { Skidding } \\
10 \text { passes; } \\
28 \mathrm{~m}^{3}\end{array}$ & $\begin{array}{l}\text { Forwarding; } \\
10 \text { passes; } \\
127 \mathrm{~m}^{3}\end{array}$ \\
\hline Before machine traffic & & & $1048(280)^{\mathrm{a}}$ & \\
\hline After 10 passes & Uphill & $\begin{array}{l}\text { InR } \\
\text { BtwR }\end{array}$ & $\begin{array}{l}1676(368)^{\mathrm{cd}} \\
1551(427)^{\mathrm{bcd}}\end{array}$ & $\begin{array}{l}2134(552)^{\mathrm{d}} \\
1096(431)^{\mathrm{ab}}\end{array}$ \\
\hline After 10 passes & Downhill & $\begin{array}{l}\text { InR } \\
\text { BtwR }\end{array}$ & $\begin{array}{l}1533(556)^{\mathrm{bc}} \\
1394(421)^{\mathrm{abc}}\end{array}$ & $\begin{array}{l}1621(437)^{\mathrm{bcd}} \\
1298(212)^{\mathrm{abc}}\end{array}$ \\
\hline
\end{tabular}

Superscript letters show statistically significant differences $(p$-value $<0.05)$ according to Kruskal-Wallis multiple-comparison test

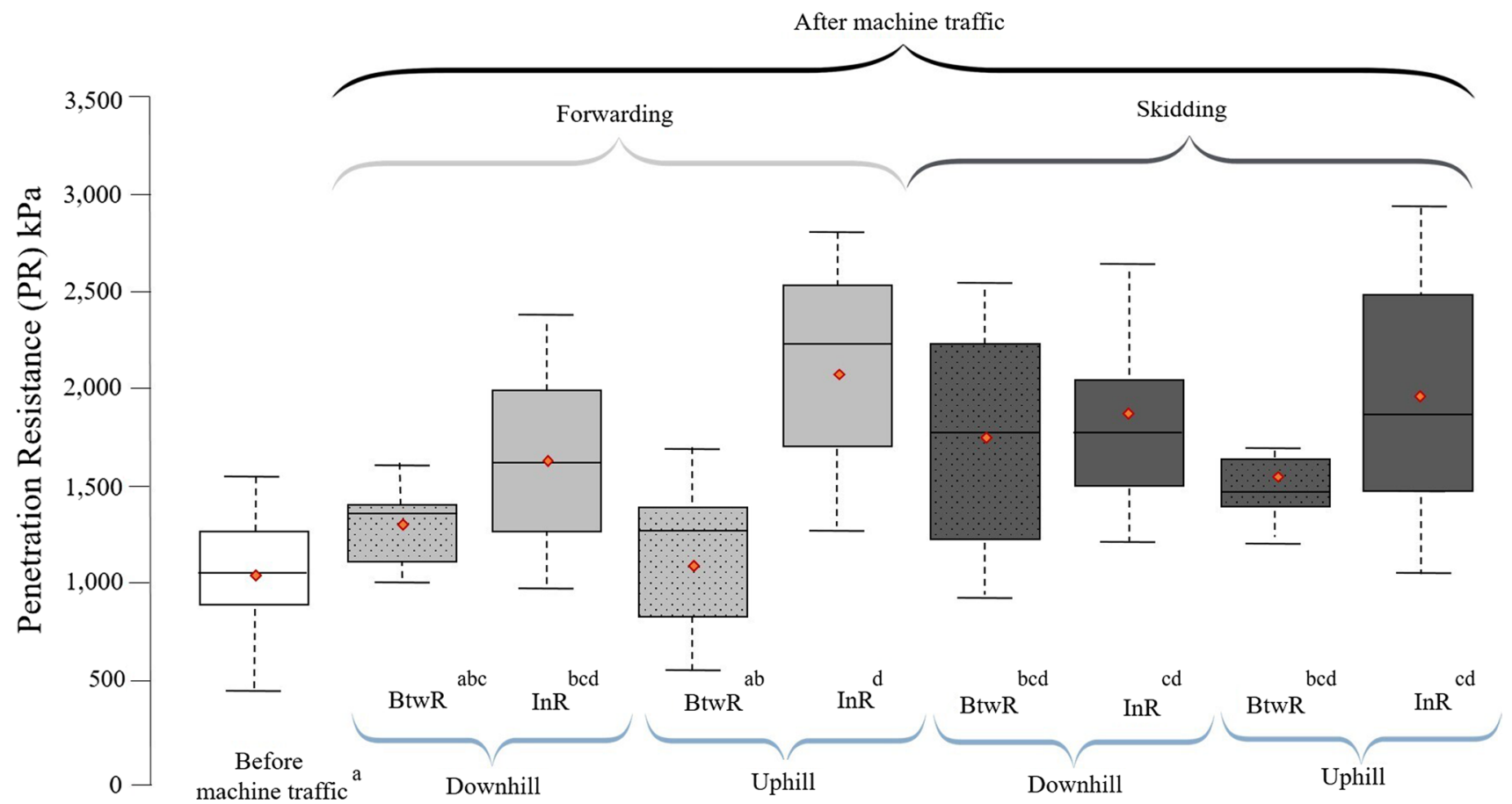

Fig. 6 Average values of penetration resistance (red diamonds) after $127 \mathrm{~m}^{3}$ of wood passed on the trails (including median and spreading range) by 10 and 45 passes for skidding and forwarding, respectively. Data about driving direction (uphill or downhill) and sam- pling zone (inside tracks-InR - and between tracks-BtwR) are included. Superscript letters show statistically significant differences $(p$-value $<0.05)$ 
warding BtwR, both in the uphill and downhill directions. The highest values were recorded in InR after forwarding and in all the skidding treatments. The PR value of forwarding BtwR uphill was significantly lower than skidding BtwR, both in the downhill and uphill directions (Fig. 6).

\section{Rut measurements}

The application of two methods-SfM and PLS- to measure the ruts due to wood extraction produced two different $3 \mathrm{D}$ reconstructions for each plot implemented in DSMs.

\section{SfM dense cloud}

The 3D reconstructions derived by SfM close-range photogrammetry had approximately 2,600,000 points for each plot $\left(144,400\right.$ points $\left./ \mathrm{m}^{2}\right)$. The errors of co-registration were always less than $0.13 \mathrm{~mm}$ for both the $x$ and $y$ coordinates, and less than $0.31 \mathrm{~mm}$ in the $z$ coordinate thus negligible for our purpose.

\section{PLS point cloud}

The $3 \mathrm{D}$ reconstruction derived by PLS had approximately $1,600,000$ points for each plot $\left(88,800\right.$ points $\left./ \mathrm{m}^{2}\right)$. The errors of co-registration were always less than $0.21 \mathrm{~mm}$ for both the $x$ and $y$ coordinates, and less than $0.31 \mathrm{~mm}$ in the $z$ coordinate thus negligible for our purpose. A total of 10 plots were elaborated with PLS instead of the 12 that had been planned, because two files containing raw data (one forwarding downhill and one skidding uphill-both after 10 passes) revealed corruption during the post-processing phase.

\section{DSMs: SfM vs. PLS}

The correspondence between the SfM and PLS methods can be easily shown in the pixel-by-pixel comparison of the resulting DSMs obtained by overlapping them. The

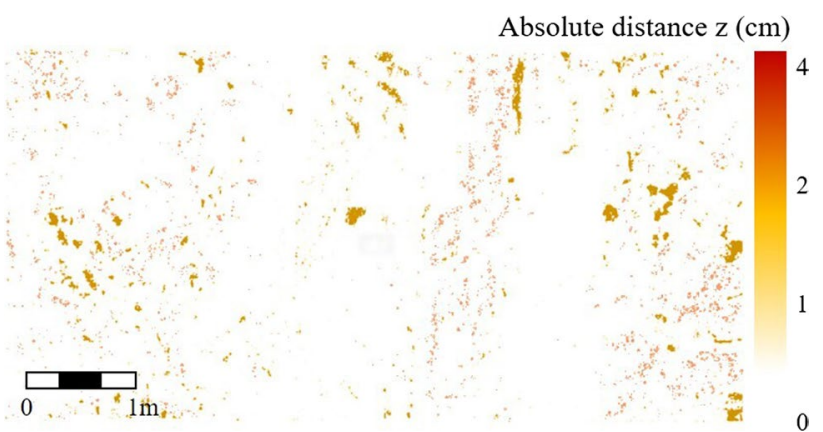

Fig. 7 Example of pixel-by-pixel comparison of digital surface models (DSM) derived by structure from motion (SfM) close-range photogrammetry and portable laser scanner (PLS) overlap of each plot showed an RMSE ranging between 2 and $4 \mathrm{~cm}$; in the $97 \%$ of the plot area the difference between the two methodologies was less than $2 \mathrm{~cm}$. A spatial representation of this comparison is reported in Fig. 7. In addition, this comparison indicates a significant relationship between the $3 \mathrm{D}$ reconstruction data of the two methods ( $R^{2}$ range between 0.97 and $0.90 ; p$ value $<0.000)$.

Moreover, the comparison between these two methodologies focus to measure ruts did not show a significant difference ( $p$ value $<0.001$ ), which reveals a similar quality and reliability of results between both methods with a good correlation $\left(R^{2} 0.80\right)$. Examples of 3D soil reconstructions derived by PLS and SfM are shown in Fig. 8.

\section{Quantification of rutting from DSMs}

Because no significant difference was recorded in the estimation of rutting using photogrammetry and PLS (Fig. 9), only the results deriving from photogrammetry are reported below. However, significant differences in VI were found in relation to wood extraction method when considering the same wood volume moved. In detail, VI after skidding $\left(7.36 \mathrm{~m}^{3} / 100 \mathrm{~m}\right.$ of trail) was almost four times higher than after forwarding $\left(1.68 \mathrm{~m}^{3} / 100 \mathrm{~m}\right.$ of trail). Conversely, the VR derived by skidding was -8.88 $\mathrm{m}^{3} / 100 \mathrm{~m}$ of trail on average, which was similar to VR after forwarding $\left(-8.51 \mathrm{~m}^{3} / 100 \mathrm{~m}\right.$ of trail). No significant differences were found in VR and VI considering the driving direction in both extraction methods.

A strong and significant positive relationship between VR and soil compaction was found $\left(R^{2} 0.704 ; p\right.$ value $<0.001)$ after $127 \mathrm{~m}^{3}$ of wood volume moved: the higher the VR, the higher the soil compaction. In contrast, the relationship between PR and BD showed a low coefficient of determination $\left(R^{2} 0.20 ; p\right.$ level $\left.<0.000\right)$.

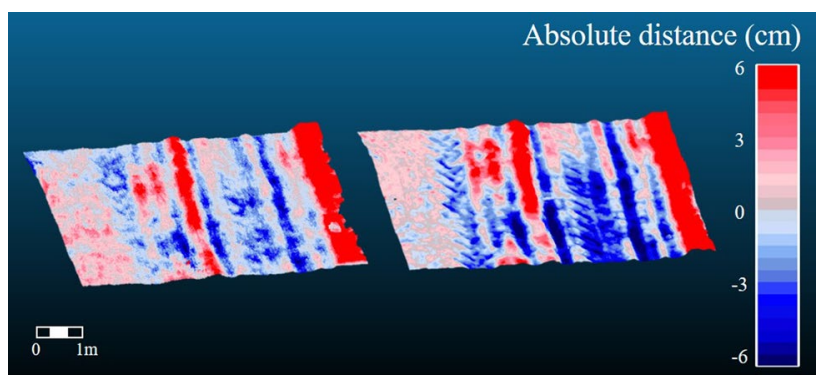

Fig. 8 Examples of 3D soil reconstructions derived by portable laser scanner (left) and structure from motion (right) showing bulge height (positive values in red) and rut depth (negative values in blue) caused by skidding 


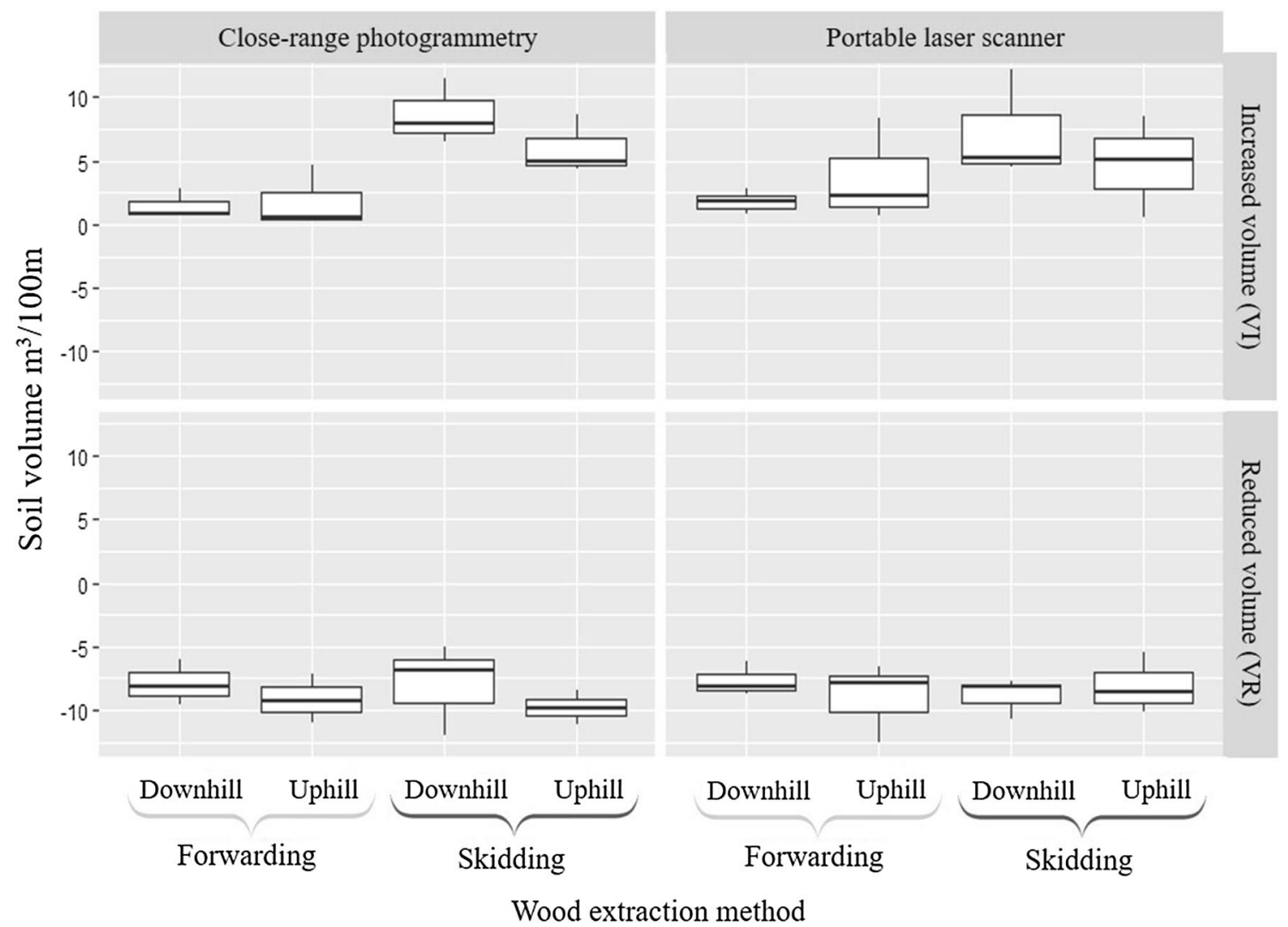

Fig. 9 Median and spreading range values obtained by digital surface model (DSM) with close-range photogrammetry and portable laser scanner of increased soil volume (VI) and reduced soil volume (VR)

\section{Discussion}

In this study, we compared the impacts (compaction and rutting) on forest soil caused by skidding and forwarding, considering both the same number of passes by loaded machine (10 passes for both skidding and forwarding) or the same volume moved $\left(127 \mathrm{~m}^{3}=10\right.$ passes for forwarding and 45 for skidding), due to the different workload capacities of the two extraction methods being examined.

\section{Physical soil parameters: BD and PR}

Our findings confirmed the general rule that the passage of a loaded ground-based machine causes soil compaction (in terms of both BD and PR increase) along the trails (Williamson and Neilsen 2003; Han et al. 2009; Cambi et al. 2015).

Indeed, BD increased for both forwarding and skidding in InR after 10 passes, driving in both uphill and downhill directions. This difference is attributed to the direct (under tyre in InR) effect of the pressure exerted on the soil. Nonetheless, a significant increase of BD was found also between undisturbed area and in BtwR, because of an indirect (between left and right tyres in BtwR) effect of the pressure per $100 \mathrm{~m}$ of trail trafficked by skidding or forwarding after $127 \mathrm{~m}^{3}$ of wood volume moved

exerted on the soil. These findings confirm that the impacts of machine traffic on soil may not be limited only to the contact area of tyres on terrain, but also on the surroundings (Solgi et al. 2016). In fact, Solgi et al. (2016) demonstrated that the soil compaction expressed as BD occurred as far as $1 \mathrm{~m}$ from the wheel ruts and increased with slope gradient and traffic intensity, which explains the differences in our results between undisturbed area and BtwR in terms of BD.

In forwarding we found a significant difference between InR and BtwR in terms of BD, with the highest impacts in InR. However, the difference between InR and BtwR is not noticeable in skidding. This distinction between skidding and forwarding may be attributable to the different forces involved in the wheel-soil interaction process and the differences in load distribution for each extraction method. During forwarding, indeed, the load is carried on the trailer and the impact on soil is caused by the pressure exerted by the machine tyres combined with wheel slippage on the ground. During skidding, in contrast, the bottom ends of the logs are lifted and connected to the winch and the top ends are dragged along the ground-thus, the impact on soil is caused by a combination of the pressure exerted by the tyres and the pressure/scarifying effect of 
the top ends of the logs. When the tyre pressure exceeds the soil bearing capacity-especially under increasing tractive demand-subsequent wheel slippage can induce pronounced shearing processes at the soil surface (Edlund et al. 2013), thereby increasing soil compaction (Eliasson and Wästerlund 2007). Therefore, although this is the case for both skidding and forwarding, during skidding the logs dragged along the skid trail exerted pressure and scarified the soil surface, thus affecting compaction, soil mixing and displacement. The significant difference between InR and BtwR found for forwarding was not recorded in skidding due to the pressure exerted by the top-ends of dragged logs in contact with the ground. Accordingly, in BtwR, it was expected that higher BDs and PRs would be found for skidding than for forwarding, due to the effect of the dragged logs on the ground. However, 10 passes of dragged logs were not sufficient to determine a significantly higher compaction in comparison with forwarding, in either downhill or uphill directions. On the contrary, after $127 \mathrm{~m}^{3}$ of wood volume moved the soil compaction was affected by the driving directions (Table 4). Nevertheless, results refer to the specific work conditions applied in this study; different lengths of logs and different distances of bottom ends from the ground could change load distribution varying the forces applied on the ground.

It is interesting to highlight that, although $\mathrm{BD}$ values were always higher after machines pass, PR showed no significant differences in BtwR for forwarding — both downhill and uphill—as well as for skidding downhill. However, PR increase for skidding downhill in BtwR became significant increasing the number of passes, i.e. considering the same wood volume moved as that of forwarding $\left(127 \mathrm{~m}^{3}\right)$. Considering these results, it appears that PR in BtwR is less affected than BD by the indirect effects of tyre pressure. In fact, the analysis of variance showed a strong influence of the wood extraction methods on BD (Table 4), difference that decreases with the increasing number of machine passes (10 forwarding and 45 skidding passes to obtain $127 \mathrm{~m}^{3}$ wood volume moved).

After $127 \mathrm{~m}^{3}$ transported, similar values of BD between skidding and forwarding were registered in uphill extraction, while in downhill operation the effects of skidding were opposite to those of forwarding considering InR/BtwR; regarding $\mathrm{PR}$, the trend seems similar, but differences were not as strong for BD.

Differences in BD levels of between uphill and downhill skidding may be explained by an uneven load distribution on the machine's axles, depending on slope direction (Jamshidi et al. 2008; Jourgholami et al. 2014) and by the increased wheel slippage and vibration encountered when skidding uphill compared to downhill. In this context, in the downhill direction, the machine's weight is more homogeneously distributed between front and rear axles. Furthermore, the weight of the logs sustained by the winch does not reduce the load on the front axle as occurs in the uphill direction. Therefore, the different distribution of weights between uphill and downhill directions implies a different application of traction force by the tractor on the ground, varying both compaction and shear effects on soils due to the threedimensional transmission of forces (Horn et al. 2007). For these reasons, in some cases the effect of dragged logs on the ground may be greater than tyre pressure, thus explaining higher BD values in BtwR than in InR in the downhill direction after skidding $127 \mathrm{~m}^{3}$. On the contrary, in the uphill direction, the tractor weight distribution is mainly on the rear axle, and the weight of logs acting on the winch increases the rear-up effect, thus concentrating the pressure of the rear axle tyres on the ground (McCallum B 1993). Moreover, the greater the slippage the greater the exposure of mineral subsoil, which naturally has a higher BD than the surface layer (Jourgholami et al. 2014), further underlining the reasons why greater BD resulted in the uphill direction, as also reported by Sidle and Drlica (Sidler and Drlica 1981). Finally, the examined machines - tractor with winch or trailer-may not be the optimal solution available in comparison with machines specifically built for forest operations (i.e. forwarder and skidder). In fact, the ground tyre pressure for the loaded trailer, $11,772 \mathrm{~kg}$ in total, was high (173 kPa on average per tyre) due to the narrow and small tyres. This could negatively affect the severity of damages on soil, that may be reduced using a skidder or a forwarder, normally equipped with larger tyres with a low pressure of inflation.

\section{Rut measurements}

The analysis of rutting after machine traffic was focused on two main aspects: (i) identifying the best method for rutting data collection and processing and (ii) assessing the effects of machine passes in terms of soil volume moved.

\section{Comparison of DSMs obtained by SfM vs. PLS}

The other aspect investigated in this study was rutting formation, analysing in depth the effects of tractors with winch or trailer in terms of both rut (volume reduced: VR) and bulge (increased volume: VI). The two methods applied and compared-PLS and SfM- have not shown significant differences in terms of results. The comparison of DSMs obtained by PLS measurements and SfM methods showed small differences (i.e. $97 \%$ of the plot area with difference $<2 \mathrm{~cm}$ ). However, the use of more precise equipment, such as a total station, can further increase the precision of soil reconstruction in both methodologies (Pierzchała et al. 2016; Starke et al. 2020). SfM is the preferred method for technical reasons; indeed, in comparison with PLS, photogrammetry has much higher resolution (almost double the point $\mathrm{m}^{-2}$ in the 
dense cloud) and spatial distribution of the point cloud. In fact, the point resolution of laser scanning clouds increases for areas closer to the PLS, whereas it decreases at longer distances, which is one of the main limitations of this technology (Nadal-Romero et al. 2015). It is therefore recommended to minimize the scanning distance when possible (Heritage and Hetherington 2007). In contrast, the resolution of multiple views with the same imaging height and overlap used in SfM were not affected by object distance (Smith and Vericat 2015). Moreover, when using PLS, the data check operation must be performed afterward (i.e. not immediately in the field). In photogrammetry, however, it is possible to check on the camera screen if the collected images are of good quality and if they correctly include the GCPs, covering the studied plot as planned, thus easily and promptly identifying and correcting errors during data collection, avoiding further field surveys in case of errors as may happen when using PLS. However, two of the main problems related to SfM are object occlusion and reflection. In the forest, vegetation (grass and/or shrubs) can cover the ground and water can reflect the signal in the rut, both compromising the accuracy of the method (Pierzchała et al. 2016), implying the necessity of choosing almost dry conditions for data collection. At the same time, one of the main problems in modelling a terrain based on a point cloud obtained by PLS is distinguishing points reflected by the terrain from those reflected by other objects (Koreň et al. 2015). In our work, we used a simple and effective filtration algorithm that removed all points located at a certain height above the ground (Koreň et al. 2015). However, the DSMs after machine traffic could be also affected by the presence of harvesting residues on the forest floor or stones overturned by skidding. In this case, a visual detection of such objects is more difficult in PLS point clouds in comparison with coloured photogrammetry point clouds' negative effects on the reliability and accuracy of the method. Nonetheless, logging residues left on the ground should be removed from the sampling area before data collection.

In conclusion, both PLS and SfM photogrammetry have increased the capacity to provide large data sets for the estimation of terrain modifications; without these technologies, the common method was manual, which was time-consuming and less reliable than PLS and SfM (Pierzchała et al. 2016; Haas et al. 2016; Marra et al. 2018).

\section{Quantification of rutting}

Photogrammetry showed interesting results on the effects of skidding and forwarding as causes of rutting. In fact, results showed that after $127 \mathrm{~m}^{3}$ of wood volume had been moved, the tractor with the winch caused ruts similar to those caused by the tractor with the trailer in terms of soil volume reduced
(VR). On the contrary, considering the increased volume (VI: bulges), skidding caused an effect four times greater than that of forwarding, with $7.36 \mathrm{~m}^{3}$ against $1.68 \mathrm{~m}^{3}$ of VI, respectively, per $100 \mathrm{~m}$ of trail. The reason for this considerable difference is the effect of log top ends dragged on the ground, and it is partially explained by what has already been discussed regarding the effects on soil physical parameters (see Discussion - physical soil parameters: BD and PR). In fact, rutting is caused by machine wheels, both in forwarding and skidding — but in skidding, the passing of the end of the dragged logs may change the impacts on soil (Wood et al. 2003; Cambi et al. 2018a). In detail, the ends of the dragged logs scratch and displace a certain quantity of soil in the dragging direction during each extraction trip. In this way, the soil is reshaped after the passage of tractor and the ruts left by the wheels are hidden. This happens especially in slope changes when the logs move and rearrange (Heninger et al. 2002; Williamson and Neilsen 2003; Agherkakli et al. 2010; Cambi et al. 2018a). Moreover, in skidding wheels cause a higher soil displacement than in forwarding due to pulling action. Looking at DSMs, rutting values are visually confirmed; in fact, in forwarding, ruts were clearly identifiable, whereas bulges along the trail were not visible. In contrast, ruts were not clearly evident on skidding trails, while bulges were. This difference negatively affected skidding in terms of risk of soil erosion, being the volume of soil moved higher than forwarding. In fact, the soil displaced by dragged logs and disturbed due to the traffic can be very vulnerable to erosion (Bagheri et al. 2013), causing negative indirect impacts on forest ecosystem, water quality and land stability (Frey et al. 2009); in this way, the measured volumes of bulges can be considered as a reference value of the potential entity of short-time erosion along the trail.

\section{Conclusions}

The main aim of this study was to describe the effects of wood extraction on both the physical properties of soil and the rutting caused by tractors with winch or trailer in different wood extraction directions. Our findings highlighted that the use of two different wood extraction methods can affect the soil impact differently in opposing driving directions. Within the limits of our experimental conditions, the study results highlighted that:

i. the role of the driving direction was found to be irrelevant when operating a four-wheel driven tractor and a trailer with one of its two axles driven. On the contrary, in order to reduce soil compaction, downhill skidding should be preferred to uphill skidding; 
ii. comparing skidding and forwarding, downhill skidding caused lower soil compaction than forwarding, while no differences were found uphill. For this reason, in downhill extraction skidding should be preferred to forwarding, while uphill-being soil compaction comparable - the choice can be made on the basis of other parameters, such as technical and logistics issues;

iii. skidding has a higher effect on soil displacement than forwarding;

In addition, our study applied and compared the performance of portable laser scanning and image-based models derived by SfM photogrammetry to evaluate soil rutting. Indeed, the use of both portable laser scanning and imagebased models derived via SfM photogrammetry were accurate methods for the creation of high-resolution DEMs and may be very useful to assess the impact of forest operations on soil. However, considering the logistics of data collection in forestry, photogrammetry is likely the best solution.

Finally, the results of this study are an important piece of knowledge aiming to reduce negative effects on soil due to ground-based extraction methods in forest operations. Following the principles of Sustainable Forest Operations (Marchi et al. 2018), modern logging operations must minimize these impacts, and this results can be useful to plan effective mitigation strategies reducing negative effects of logging on soil.

Funding This research was supported by SKIDDFORW project, funded by the University of Florence. Open access funding provided by Università degli Studi di Palermo within the CRUI-CARE Agreement.

Open Access This article is licensed under a Creative Commons Attribution 4.0 International License, which permits use, sharing, adaptation, distribution and reproduction in any medium or format, as long as you give appropriate credit to the original author(s) and the source, provide a link to the Creative Commons licence, and indicate if changes were made. The images or other third party material in this article are included in the article's Creative Commons licence, unless indicated otherwise in a credit line to the material. If material is not included in the article's Creative Commons licence and your intended use is not permitted by statutory regulation or exceeds the permitted use, you will need to obtain permission directly from the copyright holder. To view a copy of this licence, visit http://creativecommons.org/licenses/by/4.0/.

\section{References}

Agherkakli B, Najafi A, Sadeghi SH (2010) Ground based operation effects on soil disturbance by steel tracked skidder in a steep slope of forest. J for Sci 56:278-284

Agisoft (2016) 3D model reconstruction of the building
Ares A, Terry TA, Miller RE et al (2005) Ground-based forest harvesting effects on soil physical properties and douglas-fir growth. Soil Sci Soc Am J 69:1822. https://doi.org/10.2136/sssaj2004.0331

Bagheri I, Naghdi R, Jalali AM (2013) Evaluation of factors affecting soil erosion along skid trails. J Environ Sci 11:151-160

Batey T (2009) Soil compaction and soil management: a review. Soil Use Manag 25:335-345. https://doi.org/10.1111/j.1475-2743. 2009.00236.x

Bauwens S, Bartholomeus H, Calders K, Lejeune P (2016) Forest inventory with terrestrial LiDAR: a comparison of static and hand-held mobile laser scanning. Forests. https://doi.org/10.3390/ f7060127

Bosse M, Zlot R, Flick P (2012) Zebedee: design of a spring-mounted 3-D range sensor with application to mobile mapping. IEEE Trans Robot 28:1104-1119. https://doi.org/10.1109/TRO.2012.2200990

Bottinelli N, Hallaire V, Goutal N et al (2014) Impact of heavy traffic on soil macroporosity of two silty forest soils: initial effect and short-term recovery. Geoderma 217-218:10-17. https://doi.org/ 10.1016/j.geoderma.2013.10.025

Cambi M, Certini G, Neri F, Marchi E (2015) The impact of heavy traffic on forest soils: a review. For Ecol Manag 338:124-138. https://doi.org/10.1016/j.foreco.2014.11.022

Cambi M, Neri F, Marchi E et al (2016) Effects of forwarder operation on soil physical characteristics: a case study in the Italian alps. Croat J for Eng 37:233-239

Cambi M, Paffetti D, Vettori C et al (2017) Assessment of the impact of forest harvesting operations on the physical parameters and microbiological components on a Mediterranean sandy soil in an Italian stone pine stand. Eur J for Res 136:205-215. https://doi. org/10.1007/s10342-016-1020-5

Cambi M, Giannetti F, Bottalico F et al (2018a) Estimating machine impact on strip roads via close-range photogrammetry and soil parameters: a case study in central Italy. Iforest 11:148-154. https://doi.org/10.3832/ifor2590-010

Cambi M, Mariotti B, Fabiano F et al (2018b) Early response of Quercus robur seedlings to soil compaction following germination. L Degrad Dev. https://doi.org/10.1002/ldr.2912

CloudCompare Version 2.11 (2020) CloudCompare

D'Acqui LP, Certini G, Cambi M, Marchi E (2020) Machinery's impact on forest soil porosity. J Terramech 91:65-71. https://doi.org/10. 1016/j.jterra.2020.05.002

De Wit HA, Granhus A, Lindholm M et al (2014) Forest harvest effects on mercury in streams and biota in Norwegian boreal catchments. For Ecol Manag 324:52-63. https://doi.org/10.1016/j.foreco.2014. 03.044

Deconchat M (2001) Effets des techniques d'exploitation forestière sur l'état de surface du sol. Ann for Sci 58:653-661

Edlund J, Keramati E, Servin M (2013) A long-tracked bogie design for forestry machines on soft and rough terrain. J Terramech 50:7383. https://doi.org/10.1016/j.jterra.2013.02.001

Eklöf K, Schelker J, Sørensen R et al (2014) Impact of forestry on total and methyl-mercury in surface waters: distinguishing effects of logging and site preparation. Environ Sci Technol 48:4690-4698. https://doi.org/10.1021/es404879p

Eliasson L, Wästerlund I (2007) Effects of slash reinforcement of strip roads on rutting and soil compaction on a moist fine-grained soil. For Ecol Manag 252:118-123. https://doi.org/10.1016/j.foreco. 2007.06.037

Frey B, Kremer J, Rüdt A et al (2009) Compaction of forest soils with heavy logging machinery affects soil bacterial community structure. Eur J Soil Biol 45:312-320. https://doi.org/10.1016/j.ejsobi. 2009.05.006

Geoslam: Ruddington, Nottinghamshire U (2016) GeoSlam Zeb1 User Manual

Giannetti F, Chirici G, Travaglini D et al (2017) Assessment of soil disturbance caused by forest operations by means of portable laser 
scanner and soil physical parameters. Soil Sci Soc Am J. https:// doi.org/10.2136/sssaj2017.02.0051

Gondard H, Romane F, Aronson J, Shater Z (2003) Impact of soil surface disturbances on functional group diversity after clearcutting in Aleppo pine (Pinus halepensis) forests in southern France. For Ecol Manag 180:165-174. https://doi.org/10.1016/ S0378-1127(02)00597-2

Haas J, HaggeEllhöft K, Schack-Kirchner H, Lang F (2016) Using photogrammetry to assess rutting caused by a forwarder: a comparison of different tires and bogie tracks. Soil Tillage Res 163:14-20. https://doi.org/10.1016/j.still.2016.04.008

Han S-K, Han H-S, Page-Dumroese DS, Johnson LR (2009) Soil compaction associated with cut-to-length and whole-tree harvesting of a coniferous forest. Can J for Res 39:976-989. https://doi.org/ 10.1139/X09-027

Heninger R, Scott W, Dobkowski A et al (2002) Soil disturbance and 10 -year growth response of coast Douglas-fir on nontilled and tilled skid trails in the Oregon Cascades. Can J for Res 32:233246. https://doi.org/10.1139/x01-195

Heritage G, Hetherington D (2007) Towards a protocol for laser scanning in fluvial geomorphology. Earth Surf Process Landforms 32:66-74

Hijmans RJ, Etten J Van, Sumner M, et al (2020) CRAN: package raster

Horn R, Vossbrink J, Peth S, Becker S (2007) Impact of modern forest vehicles on soil physical properties. For Ecol Manag 248:56-63. https://doi.org/10.1016/j.foreco.2007.02.037

Jamshidi R, Jaeger D, Raafatnia N, Tabari M (2008) Influence of two ground-based skidding systems on soil compaction under different slope and gradient conditions. Int J for Eng 19:9-16. https://doi. org/10.1080/14942119.2008.10702554

Jansson KJ, Wasterlund I (1999) Effect of traffic by lightweigth foret machinery on the growth of young Picea abies trees. Scand J for Res 14:581-588

Jester W, Klik A (2005) Soil surface roughness measurement-methods, applicability, and surface representation. CATENA 64:174192. https://doi.org/10.1016/J.CATENA.2005.08.005

Jourgholami M, Soltanpour S, Abari ME, Zenner EK (2014) Influence of slope on physical soil disturbance due to farm tractor forwarding in a Hyrcanian forest of Northern Iran. Iforest 7:342-348. https://doi.org/10.3832/ifor1141-007

Jourgholami M, Khajavi S, Labelle ER (2020) Recovery of forest soil chemical properties following soil rehabilitation treatments: an assessment six years after machine impact. Croat $\mathbf{J}$ for Eng 41:163-175. https://doi.org/10.5552/crojfe.2020.620

Koreň M, Slančík M, Suchomel J, Dubina J (2015) Use of terrestrial laser scanning to evaluate the spatial distribution of soil disturbance by skidding operations. Iforest 8:386-393. https://doi.org/ 10.3832/ifor1165-007

Lanford BL, Stokes BJ (1995) Comparison of two thinning systems. Part 1. Stand and site impacts. For Prod J 45:74-79

Lee E, Li Q, Eu S et al (2020) Assessing the impacts of log extraction by typical small shovel logging system on soil physical and hydrological properties in the Republic of Korea. Heliyon 6:e03544. https://doi.org/10.1016/j.heliyon.2020.e03544

Marchi E, Picchio R, Spinelli R et al (2014) Environmental impact assessment of different logging methods in pine forests thinning. Ecol Eng 70:429-436. https://doi.org/10.1016/j.ecoleng.2014.06. 019

Marchi E, Chung W, Visser R et al (2018) Sustainable forest operations (SFO): a new paradigm in a changing world and climate. Sci Total Environ 634:1385-1397. https://doi.org/10.1016/j.scito tenv.2018.04.084

Mariotti B, Hoshika Y, Cambi M et al (2020) Vehicle-induced compaction of forest soil affects plant morphological and physiological attributes: a meta-analysis. For Ecol Manag 462:118004. https:// doi.org/10.1016/j.foreco.2020.118004

Marra E, Cambi M, Fernandez-Lacruz R et al (2018) Photogrammetric estimation of wheel rut dimensions and soil compaction after increasing numbers of forwarder passes. Scand J for Res. https:// doi.org/10.1080/02827581.2018.1427789

McCallum B (1993) Equipping the farm tractor for forest operatios. FERIC Handbook No.1, Forest Engineering Research Institute of Canada. ISSN 0701-8355

Nadal-Romero E, Revuelto J, Errea P, López-Moreno JI (2015) The application of terrestrial laser scanner and SfM photogrammetry in measuring erosion and deposition processes in two opposite slopes in a humid badlands area (central Spanish pyrenees). SOIL 1:561-573. https://doi.org/10.5194/soil-1-561-2015

Naghdi R, Solgi A, Zenner EK (2015) Soil disturbance caused by different skidding methods in mountainous forests of Northern Iran. Int J for Eng 26:212-224. https://doi.org/10.1080/14942119.2015. 1099814

Naghdi R, Solgi A, Labelle ER, Nikooy M (2020) Combined effects of soil texture and machine operating trail gradient on changes in forest soil physical properties during ground-based skidding. Pedosphere 30:508-516. https://doi.org/10.1016/S1002-0160(17) 60428-4

Picchio R, Maesano M, Savelli S, Marchi E (2009) Productivity and energy balance in conversion of a Quercus cerris L. coppice stand into high forest in Central Italy. Croat J for Eng 30:15-26

Pierzchała M, Talbot B, Astrup R (2014) Estimating soil displacement from timber extraction trails in steep terrain: application of an unmanned aircraft for 3D modelling. Forests 5:1212-1223. https:// doi.org/10.3390/f5061212

Pierzchała M, Talbot B, Astrup R (2016) Measuring wheel ruts with close-range photogrammetry. Forestry 89:383-391. https://doi. org/10.1093/forestry/cpw009

R Development Core Team (2020) R: a language and environment for statistical computing. version 3602020

Ryding J, Williams E, Smith MJ, Eichhorn MP (2015) Assessing handheld mobile laser scanners for forest surveys. Remote Sens 7:1095-1111. https://doi.org/10.3390/rs70101095

Schneider CT (1991) 3-D vermessung von oberflächen und bauteilen durch photogrammetrie und bildverarbeitung. In: Proceedings of the IDENT/VISION '91. pp 14-17

Sidler RC, Drlica D (1981) Soil compaction from logging with a lowground pressure skidder in the oregon coast. Soil Sci Soc Am J 45:1219-1224

Siegel-Issem CM, Burger J, Powers R et al (2005) Seedling root growth as a function of soil density and water content. Soil Sci Soc Am J 69:215-226

Sirén M, Ala-Ilomäki J, Mäkinen H et al (2013) Harvesting damage caused by thinning of Norway spruce in unfrozen soil. Int $\mathbf{J}$ for Eng 24:60-75. https://doi.org/10.1080/19132220.2013.792155

Smith MW, Vericat D (2015) From experimental plots to experimental landscapes: topography, erosion and deposition in sub-humid badlands from structure-from-motion photogrammetry. Earth Surf Process Landforms 40:1656-1671. https://doi.org/10.1002/esp. 3747

Solgi A, Najafi A, Ezzati S, Ferencik M (2016) Assessment of groundbased skidding impacts on the horizontally rate and extent of soil disturbance along the margin of the skid trail. Ann for Sci 73:513522. https://doi.org/10.1007/s13595-016-0544-7

Solgi A, Naghdi R, Marchi E et al (2019) Impact assessment of skidding extraction : effects on physical and chemical properties of forest soils and on maple seedling growing along the skid trail. Forests 10:1-17. https://doi.org/10.3390/f10020134

Spinelli R, Magagnotti N, Nati C (2010) Benchmarking the impact of traditional small-scale logging systems used in Mediterranean 
forestry. For Ecol Manage 260:1997-2001. https://doi.org/10. 1016/j.foreco.2010.08.048

Starke M, Derron C, Heubaum F, Ziesak M (2020) Rut depth evaluation of a triple-bogie system for forwarders-field trials with TLS data support. Sustain. https://doi.org/10.3390/SU12166412

Sugai T, Yokoyama S, Tamai Y et al (2020) Evaluating soil-root interaction of hybrid larch seedlings planted under soil compaction and nitrogen loading. Forests 11:1-14. https://doi.org/10.3390/ f11090947

Talbot B, Rahlf J, Astrup R (2018) An operational UAV-based approach for stand-level assessment of soil disturbance after forest harvesting. Scand J for Res 33:387-396. https://doi.org/10. 1080/02827581.2017.1418421

Van Rossum G, Drake FL (2020) The python reference manual. 3-4
Williamson JR, Neilsen WA (2003) The effect of soil compaction, profile disturbance and fertilizer application on the growth of eucalypt seedlings in two glasshouse studies. Soil Tillage Res 71:95-107. https://doi.org/10.1016/S0167-1987(03)00022-9

Wood MJ, Carling PA, Moffat AJ (2003) Reduced ground disturbance during mechanized forest harvesting on sensitive forest soils in the UK. Forestry 76:345-361. https://doi.org/10.1093/forestry/ 76.3 .345

Publisher's Note Springer Nature remains neutral with regard to jurisdictional claims in published maps and institutional affiliations. 